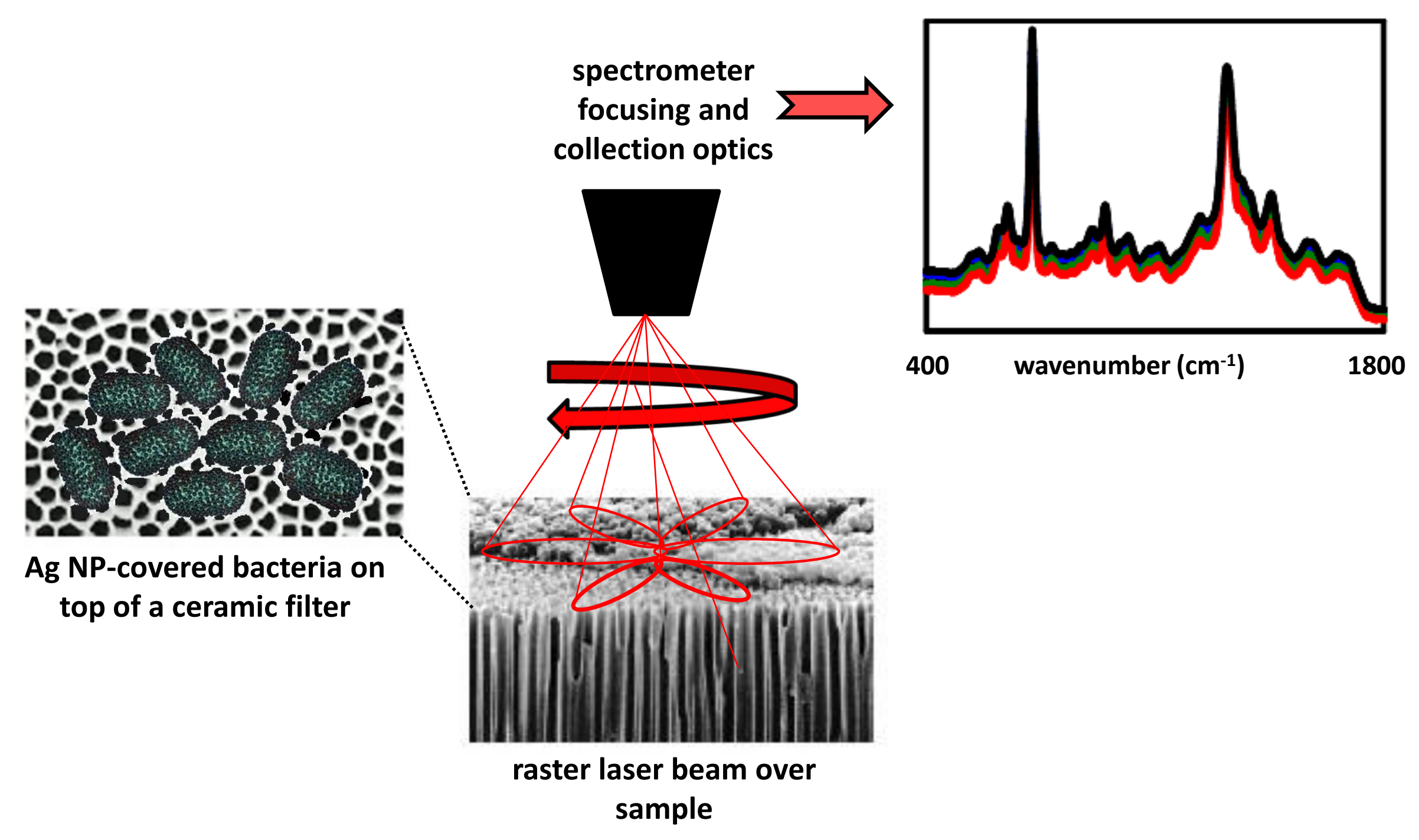

(c) 2017. This manuscript version is made available under the Elsevier user license http://www.elsevier.com/open-access/userlicense/1.0/ 


\title{
SERS Substrates Fabricated using Ceramic Filters for the Detection of Bacteria: Eliminating the Citrate Interference
}

\author{
P.A. Mosier-Boss ${ }^{1}$ \\ K.C. Sorensen, R.D. George, and P.C. Sims
}

A. O'braztsova

\begin{abstract}
It was found that spectra obtained for bacteria on SERS substrates fabricated by filtering citrate-generated $\mathrm{Ag}$ nanoparticles (NPs) onto rigid, ceramic filters exhibited peaks due to citrate as well as the bacteria. In many cases the citrate spectrum overwhelmed that of the bacteria. Given the simplicity of the method to prepare these substrates, means of eliminating this citrate interference were explored. It was found that allowing a mixture of bacteria suspension and citrategenerated Ag NPs to incubate prior to filtering onto the ceramic filter eliminated this interference.
\end{abstract}

Keywords: SERS; bacteria; ceramic filter; orbital raster scan; citrate

\section{INTRODUCTION}

Earlier a simple method of preparing SERS substrates to obtain SERS spectra of bacteria was described [1]. In this method Ag or Au colloidal particles were filtered onto a ceramic filter. A bacterial suspension was then filtered onto the surface of the prepared SERS substrate. This method homogeneously distributed the bacteria on the surface of the substrate. SERS spectra 
were then measured using a portable, inexpensive Raman system with orbital raster scan (ORS) capability. The advantage of rastering is that a large sample area is scanned which efficiently interrogates those regions of the substrate that exhibit the greatest SERS activity (i.e., SERS active hot spots) [2]. This sampling approach collectively increases the SERS signal by averaging the SERS active hotspots, which have a more intense Raman signature than the interference from the surrounding substrate. This greatly increases both sensitivity and resolution. However, it was later found that using citrate-generated Ag nanoparticles in the method described in [1] resulted in spectra that were dominated by peaks due to citrate [3, 4]. It has been shown that citrate-reduced Ag NPs are stabilized by a surface layer of silver citrates, with pendant negative groups [5]. However, aggregation of the Ag NPs is required to obtain a spectrum of the citrate [3]. Concentrating the citrate-generated Ag NPs on the ceramic membrane made this possible and the resultant spectra exhibited peaks due to citrate [1]. Additional smaller peaks were observed that are attributed to the bacteria.

This method of preparing SERS substrates has the advantage of assuring a homogeneous distribution of bacteria on the surface. Because of this benefit, several approaches for eliminating the citrate interference were examined. One method described by Pinkhasova et al. [6] used thermal annealing after immobilizing Ag NPs prepared by the citrate reduction process on an anodized aluminum oxide surface. The SERS platforms then underwent heat treatment at 200, 300, 400, and $600{ }^{\circ} \mathrm{C}$ in a quartz tube furnace under ambient air. At $400{ }^{\circ} \mathrm{C}$, the citrate pendant groups were completely removed and $\operatorname{Ag}_{2} \mathrm{O}$ decomposed to metallic Ag. These heat treated substrates exhibited high SERS enhancements. This process was applied to citrate generated Ag NPs immobilized on $0.02 \mu \mathrm{m}$ pore size Anodisc filters. However, after the heat treatment, the SERS enhancement was quenched. Another method that was investigated was the direct reduction of Ag on the surface of the bacteria to form a 'wall colloid' [7-9]. This process has multiple steps. These steps are: (1) immerse cells in sodium borohydride solution for $\sim 1 \mathrm{~min}$, (2) spin suspension to form a pellet, (3) remove sodium borohydride solution, (4) wash cells, (5) spin suspension to form a pellet, (6) remove supernatant, (7) add $\mathrm{AgNO}_{3}$ solution and suspend cells, (8) after $\sim 5$ min spin suspension to form a pellet (pellet should be black), (9) remove $\mathrm{AgNO}_{3}$ solution, (10) wash cells, (11) spin suspension to form a pellet, and (12) remove supernatant, and finally (13) add water, suspend cells, and filter onto a $0.02 \mu \mathrm{m}$ pore size 
Anodisc filter. Cells are lost throughout this process. A SERS spectrum was obtained that exhibited weak signals from the bacteria, but it was on top of a broad fluorescence background.

Citrate-generated Ag NPs are commonly used to obtain SERS spectra of bacteria [10-14]. In all of these studies, the bacteria and citrate-generated Ag NPs were mixed together before the samples were placed on a surface to dry. The SERS spectra obtained for these samples do not show any peaks due to citrate. The implication of these observations is that, given time, bacteria displace the citrate on the Ag NPs. To test this, experiments were conducted by mixing bacteria samples with citrate-generated Ag NPs prior to filtering onto a ceramic membrane. The results of these experiments are discussed in this communication.

\section{EXPERIMENTAL}

\subsection{Reagents and Bacteria}

Silver nitrate (Aldrich), sodium citrate dihydrate (Aldrich), boric acid (Sigma-Aldrich), sodium hydroxide (Fisher Scientific), and water (molecular biology grade (MBG), SigmaAldrich; RNA grade, Fisher; or HPLC grade, Aldrich) were used per manufacturer specifications. Luria-Bertani (LB) broth, used to grow the bacterial cells, was prepared from Difco $^{\mathrm{TM}}$ powder (BD) according to the manufacturer specifications.

Bacterial strains used in this study included: Escherichia coli (E. coli) K-12 American Type Culture Collection (ATCC); Shewanella putrefaciens (S. putrefaciens) CN32 (provided in

kind by Dr. Bretschger, JCVI, San Diego, CA); as well as Pseudomonas aeruginosa (P. aeruginosa) $\mathrm{P} 1, \mathrm{P} 2$, and $\Delta \mathrm{mrtv}$ (provided in kind by Dr. Zaborina, University of Chicago, IL).

\subsection{Preparation of Ag Colloid}

The Lee-Meisel [15] process was used to prepare citrate derived Ag colloid in suspension. A Teflon ${ }^{\circledR}$-coated stir bar and a $250 \mathrm{~mL}$ solution containing $45 \mathrm{mg}$ of silver nitrate were placed in a two-neck $500 \mathrm{~mL}$, round bottom flask. A condenser was placed on one neck of the flask. A $25 \mathrm{~mL}$ addition funnel containing $5 \mathrm{~mL}$ of $1 \%$, by weight, sodium citrate solution was placed on the second neck of the flask. Once the silver nitrate solution came to a boil, the sodium citrate solution was added rapidly with constant stirring. After refluxing, with constant 
stirring, for one hour, the reaction flask was removed from the heat and allowed to cool to room temperature. The resultant colloidal suspension was yellowish-gray in color. The citrate-derived Ag colloid suspension was transferred to a clean, amber bottle and stored at $4{ }^{\circ} \mathrm{C}$ until use.

\subsection{Preparation of Borate Buffer}

The $0.1 \mathrm{M}$ borate buffer was made by dissolving $1.237 \mathrm{~g}$ of boric acid in $100 \mathrm{~mL} \mathrm{MBG}$ water. The $\mathrm{pH}$ of a $50 \mathrm{~mL}$ portion of this solution was adjusted to 7.1-7.2 using a 0.1 M sodium hydroxide solution. Once the $\mathrm{pH}$ was adjusted, the solution was diluted to $100 \mathrm{~mL}$.

\subsection{Preparation of Microorganism}

Bacterial strains were cultured in $\mathrm{LB}$ broth $\left(\mathrm{Difco}^{\mathrm{TM}}, \mathrm{BD}\right)$ either from frozen stocks or from colonies grown on LB agar plates and maintained on liquid medium, in $15 \mathrm{~mL}$ conical sterile tubes, by periodic transfers. To prepare a sample for SERS measurements, a 0.2-0.3 mL aliquot of the cell suspension was transferred to a cultivation tube containing $5 \mathrm{~mL}$ of LB broth. Microorganisms were then incubated overnight at $37^{\circ} \mathrm{C}$. Cells were harvested by centrifugation. This was done by placing an aliquot of the bacterial sample in a $2 \mathrm{~mL}$ Eppendorf tube and spinning it down using an AccuSpin ${ }^{\mathrm{TM}}$ Micro 17R centrifuge (Fisher Scientific) at 10,000 x g for 1 min. The supernatant was discarded and the cell pellet was re-suspended in borate buffer solution. The sample was then re-centrifuged at 10,000 x g for $1 \mathrm{~min}$, the supernatant discarded, and re-suspended the same as described above. This process was repeated four more times to remove all residual LB broth [16]. Following removal of all residual media, cells were resuspended in buffer up to a cell concentration of $\sim 1 \times 10^{8}$ cells $\mathrm{mL}^{-1}$. Cell concentration was determined based on an established linear relationship between optical density and cell concentration [1]. Per established methods, an OD of $600 \mathrm{~nm}$ was determined using a S2100UV ${ }^{+}$ $\left(\mathrm{UNICO}^{\circledR}\right)$ spectrophotometer.

\subsection{SERS Measurements}

SERS measurements were made using a Snowy Range Instruments Sierra portable Raman system. This system has a $785 \mathrm{~nm}$ laser that can operate between 2 and $100 \mathrm{~mW}$; a 2048 pixel, linear, TE cooled to $-10{ }^{\circ} \mathrm{C}$, NIR enhanced CCD array; and a dispersive spectrometer (operational range is $200-3200 \mathrm{~cm}^{-1}$ and a resolution of $8 \mathrm{~cm}^{-1}$ ). This particular system has threeway sampling for side, bottom, and 'point and shoot' [17]. A knob on the side of the instrument 
either directs the laser beam into a sample chamber for side and bottom measurements of vials/cuvettes or below and outside of the instrument in the 'point and shoot' orientation to measure surfaces. The instrument was operated in the latter 'point and shoot' orientation to obtain SERS spectra of the bacteria samples in orbital raster scan (ORS) mode, in which a small spot size laser (30 microns) was rapidly scanned (rastered) over a larger sample area (typically $\left.20 \mathrm{~mm}^{2}\right)$.

\section{RESULTS AND DISCUSSION}

\subsection{Mixing Bacteria and Citrate-generated Ag NPs Prior to Filtering onto a Ceramic Membrane}

As discussed vide supra, others [10-14] have used citrate-generated Ag NPs to obtain SERS spectra of bacteria. In these earlier investigations, the Ag NPs and the bacteria are mixed prior to placing the mixture onto a flat surface to dry. It has been shown that when biological agents are mixed with nanosilver, they displace the non-covalently bound surface-coating agent present on the Ag NPs [18]. In this investigation, experiments were conducted by mixing bacteria samples with citrate-generated Ag NPs prior to filtering onto a ceramic membrane to see if this would eliminate the citrate interference.

Figure 1a shows the SERS spectrum of citrate that coats the surface of the citrategenerated Ag NPs. This spectrum was obtained by filtering $3 \mathrm{~mL}$ of the citrate-generated $\mathrm{Ag}$ colloid onto a $25 \mathrm{~mm}$ diameter, $0.02 \mu \mathrm{m}$ Anodisc filter. The peak positions and assignments for citrate are summarized in Table 1. The peaks due to citrate dominated the spectra shown in our previous report [1]. Figures $1 \mathrm{~b}$ and $1 \mathrm{c}$ summarize the results obtained by mixing equal volumes

of citrate-generated Ag NPs and $\sim 10^{8}$ cells $/ \mathrm{mL}$ samples of E. coli. The volumes of Ag colloid and E. coli suspension used to prepare the samples and the total cell numbers on the filter are indicated in the figure caption. The samples were allowed to equilibrate for one hour, overnight, and one week prior to filtering onto a $25 \mathrm{~mm}$ diameter, $0.02 \mu \mathrm{m}$ pore size Anodisc filter. Samples were allowed to air dry prior to obtaining the spectra.

Figure $1 \mathrm{~b}$ shows the results obtained after equilibrating the bacteria and citrate-generated Ag NPs for one hr, under ambient conditions, and overnight, in the refrigerator. Both 
suspensions, prior to filtering, were yellow-gray in color, i.e., no settling of the nanoparticles was observed. The two spectra overlap. Figure 1c shows the results obtained after equilibrating the bacteria and citrate-generated Ag NPs for one week in the refrigerator. After one week, two layers were observed. The bottom layer was comprised of a suspension of black particles and the top layer was clear. This indicated that the Ag NPs had coalesced around the bacteria. The black particles were re-suspended and filtered onto a $0.02 \mu \mathrm{m}$ pore size Anodisc membrane. The features of the spectrum shown in Figure 1c are a little broader than those shown in Figure 1b. The spectrum in Figure 1c also exhibits a broader SERS continuum than that observed in Figure 1b. However, the spectra in Figures $1 \mathrm{~b}$ and $1 \mathrm{c}$ are very similar. It should be noted that the spectra shown in Figure 1b were generated from E. coli prepared in the same batch while the spectrum in Figure 1c was generated from E. coli from a different batch. This shows that E. coli from different batches yield similar spectra, demonstrating that this method of preparing samples and obtaining SERS spectra is reproducible.

In the spectra shown in Figures $1 \mathrm{~b}$ and $1 \mathrm{c}$, the citrate peaks are either eliminated or greatly reduced. The data also indicate that one hour of equilibration time is sufficient to displace the citrate on the surface of the Ag NPs. The spectra in Figures 1b and 1c look very similar to those obtained for E. coli on Ag NPs prepared using the $\mathrm{NH}_{2} \mathrm{OH}$ reduction process [19] and for E. coli that had been vortexed with citrate-generated Ag NPs and then dropped onto a $\mathrm{CaF}_{2}$ slide [11]. In the $\mathrm{NH}_{2} \mathrm{OH}$ reduction process [20], the Ag NPs are prepared in-situ by first soaking the bacteria in a silver nitrate solution and then using $\mathrm{NH}_{2} \mathrm{OH}$ as a reducing agent. The resultant 'colloid wall' forms directly on the cell wall of the bacterium, as shown by TEM imaging, and the resultant Ag NPs are not capped by the reducing agent.

An experiment was conducted that varied the ratio of the bacteria suspension and the citrate-generated Ag NPs. The purpose of this experiment was to determine if there was an optimum ratio to obtain SERS spectra. In this experiment $500 \mu \mathrm{L}$ aliquots of $E$. coli, each containing $9.5 \times 10^{7}$ cells, were mixed with $250,500,1000$, and $1500 \mu \mathrm{L}$ of citrate-generated $\mathrm{Ag}$ NPs. The samples were allowed to equilibrate overnight and then were filtered onto $13 \mathrm{~mm}$ diameter, $0.1 \mu \mathrm{m}$ pore size Anodisc filter. After the filtered samples had air dried, SERS spectra were obtained. The results are summarized in Figure 2. It can be seen that the spectrum 
exhibiting the largest SERS intensity and minimum continuum was obtained by mixing equal amounts of bacteria and citrate-generated Ag NPs. The significance of the spectral changes observed in Figure 2 will be discussed vide infra in section 3.3. However, Smith-Palmer et al. [20] observed similar results when they mixed $P$. aeruginosa biofilms with varying amounts of silver colloid and looked at the SERS intensity of the biofilm as a function of the colloid:bacteria ratio. Initially, the SERS signal increased as the amount of colloid increased. Eventually a colloid:bacteria ratio was reached that gave a maximum SERS signal. For ratios greater than this, the SERS signal decreased.

\subsection{Rastering/Non-rastering of Laser, Homogeneity, Sample Longevity, and Concentration Response}

Additional experiments were conducted using samples prepared by mixing equal volumes of E. coli suspensions and citrate-derived Ag NPs. The samples were allowed to equilibrate overnight prior to filtering onto Anodisc filters. Experiments were performed to examine the effect of rastering/non-rastering the laser over the sample and to determine sample homogeneity. SERS spectra of a sample were measured periodically to determine how long the sample remained SERS active. Another set of experiments was performed to determine the concentration response.

Figure 3a shows spectra of $E$. coli obtained using single point mode as well as rastering the laser over the sample. Both spectra were obtained using the same laser power and acquisition time. The single spot spectrum is of low quality. In the region between $1000-1800 \mathrm{~cm}^{-1}$, the spectral resolution is poor. The SERS spectrum obtained by rastering the laser over the sample results in more intense, better resolved peaks. Rastering allows one to quickly scan a large area to more efficiently interrogate SERS active hot spots. Consequently, this sampling approach increases the SERS signal by averaging the SERS active hot spots, which have a more intense Raman signature than the surrounding substrate.

The observed signal intensity of SERS spectra is a function of both the sample distribution and the number of hot spots probed. To prepare the sample for SERS analysis [1], a $25 \mathrm{~mm}$ diameter, $0.02 \mu \mathrm{m}$ pore size Anodisc filter is placed on top of the frit of a vacuum filter 
funnel. The fluted part of the filter funnel is then clamped on top of the ceramic filter. The Ag NPs-bacteria suspension is then pipetted into the funnel and a vacuum is used to concentrate the Ag NP-coated bacteria onto the surface of the filter. Given this method of preparation, it is expected that the distribution of the Ag-NP coated bacteria will be homogeneous on the surface of the filter. To demonstrate this, spectra of E. coli were obtained by rastering the laser over five non-overlapping regions on the substrate that was prepared after one hour of equilibration between the bacteria and the citrate-generated Ag NPs. A schematic of the areas measured in shown in Figure 3b. The resultant spectra are also shown. It can be seen that all five spectra overlap. This would not be the case if the sample distribution and/or number of hot spots were not similar for each region that was sampled. Consequently, the results summarized in Figure $3 \mathrm{~b}$ indicate that the resultant film on the ceramic membrane is of a uniform thickness and that the distribution of bacteria on the surface is homogeneous. Therefore, a Raman microscope would not be needed to locate and obtain a spectrum of the bacteria.

To evaluate shelf-life, a sample of E. coli and citrate-generated Ag NPs was prepared. After equilibrating overnight, the sample was filtered onto a $25 \mathrm{~mm}$ diameter, $0.02 \mu \mathrm{m}$ Anodisc filter. Cytoseal 60 was used to affix a cover slip over this sample to protect the surface. The sample was stored at $4{ }^{\circ} \mathrm{C}$. Periodically, over a seven month period, a SERS spectrum of the sample was measured. These SERS spectra are shown in Figure 4. In general, the features of the sample spectrum were observed to stay relatively constant, indicating that the sample has not degraded.

SERS spectra were obtained for three separate cultures of E. coli. The numbers of cells were varied and the results are summarized in Figure 5. Equal volumes of bacterial suspension and citrate-generated Ag NPs were used, except for the sample that yielded the spectrum shown in Figure 5a. To obtain the spectrum shown in Figure 5a, $4 \mathrm{~mL}$ of the bacterial suspension was mixed with $1.5 \mathrm{~mL}$ of the citrate-generated Ag NPs. The samples were allowed to equilibrate overnight prior to filtering onto a $0.1 \mu \mathrm{m}$ pore size Anodisc filter. Figure 5 summarizes the number of cells on the filter, the diameter of the filter used, as well as the acquisition time and the number of spectra averaged. Smaller diameter filters were used when sample volumes (bacteria suspension and Ag NPs) were between 200 and $1000 \mu \mathrm{L}$. This assured that the resultant 
film was thick enough to obtain good SERS spectra. As shown in Figure 5, similar spectra were obtained within a given culture. There were some differences in intensity of some peaks between the three different cultures. This variability is indicative of differences in cell surface composition possibly in response to environmental conditions [21]. However, this needs to be investigated further.

\subsection{The Nature of the Interaction between Bacteria and Ag NPs}

The antimicrobial properties of silver have been known for thousands of years. Both SEM [22-25] and TEM [22-24, 26] images have been taken of bacterial cells, including E. coli, that have been exposed to Ag NPs. Native cells exhibit smooth, undamaged surfaces. TEM images show a multilayered cell surface consisting of an outer membrane, peptidoglycan layer in the periplasmic space, and a cytoplasmic membrane [22]. However, Ag NPs treated cells become damaged. SEM photomicrographs show multiple depressions and indentations on the surface. TEM images show either localized or complete separation of the cell membrane from the cell wall. The images show that the nanoparticles anchor the cell at several locations and cause damage at various sites in the membrane, which could result in cell lysis. The SEM/TEM results indicate that the Ag NPs partition through the polysaccharide capsule, which most bacteria have, and directly bind to the cell wall. During this interaction, the citrate molecules on the Ag NPs are displaced [18]. It is likely that the citrate capping agent enables the Ag NPs to partition through the capsules of bacteria. Both in vitro and in vivo studies have shown that the antibacterial activity of silver nanoparticles depends on the capping agent [27]. Borate-silver nanoparticles were inactive against Salmonella whereas citrate-silver and PVP-silver exhibited antibacterial activity. It has been shown that Ag NPs produced by the sodium borohydride reduction method are uncapped [28] while citrate and PVP are capping agents commonly used to stabilize Ag colloids.

This partitioning through the capsule may explain the results summarized in Figure 2. In this experiment $500 \mu \mathrm{L}$ aliquots of $E$. coli, containing $9.5 \times 10^{7}$ cells, were mixed with 250,500 , 1000 , and $1500 \mu \mathrm{L}$ of citrate-generated Ag NPs. The 500, 1000, and $1500 \mu \mathrm{L}$ citrate-generated Ag NPs gave spectra that exhibit peaks of approximately the same relative peak intensities. However, the 1000 and $1500 \mu \mathrm{L}$ citrate-generated Ag NPs spectra show an overall decrease in 
peak intensity and exhibit a stronger fluorescence background compared to the $500 \mu \mathrm{L} \mathrm{Ag} \mathrm{NPs}$ sample. As discussed vide supra, these SERS spectra are similar to those obtained by Zhou et al. [19] when they prepared a wall colloid directly on the surface of the cell wall. This was verified by TEM imaging [19]. Consequently, the SERS spectra for the samples prepared using the 500, 1000, and $1500 \mu \mathrm{L}$ citrate-generated Ag NPs indicate that NPs have completely penetrated the capsule and have bound to the cell wall. The increased fluorescence observed in the spectra obtained for the 1000 and $1500 \mu \mathrm{L}$ samples may be indicative of damage to the cell walls of the bacteria resulting in leakage of the cellular contents. High fluorescence backgrounds have been observed when sodium borohydride was used to reduce silver ions adsorbed onto the bacteria. The decrease in the SERS intensity of the peaks shown in Figure 2 may also be the result of degradation of the cell wall.

In contrast to the spectra obtained for the 500,1000, and $1500 \mu \mathrm{L}$ citrate-generated $\mathrm{Ag}$ NPs, the spectrum obtained using $250 \mu \mathrm{L}$ of citrate-generated Ag NPs shows additional peaks. Also the intensities of the peaks are weaker for the $250 \mu \mathrm{L}$ sample. This spectrum is similar to that obtained by Zhou et al. [19] when they mixed E. coli suspension with Ag NPs prepared by reducing silver ions with hydroxylamine hydrochloride. The resultant Ag NPs are uncapped. TEM imaging showed that the hydroxylamine generated Ag NPs were not adhered to the cell wall of the bacterium [19]. The implication for the $250 \mu \mathrm{L}$ spectrum shown in Figure 2 is that some Ag NPs have penetrated the bacterial capsules and were in contact with the cell walls of the bacteria. However, other Ag NPs were trapped inside the capsules and the additional peaks observed in the SERS spectrum are likely due to the acidic polysaccharides present in the capsules [29].

\subsection{SERS of Other Bacterial Species/Strains}

In this study SERS spectra were obtained for three different species of bacteria (Escherichia coli ATCC, Shewanella putrefaciens CN32, and Pseudomonas aeruginosa) as well as three different strains of Pseudomonas aeruginosa $(P 1, P 2$, and $\Delta m v t r)$. All three species of bacteria are Gram-negative [1]. Samples were prepared by mixing $1.5 \mathrm{~mL}$ of bacteria suspensions with $1.5 \mathrm{~mL}$ of citrate generated Ag NPs and were allowed to equilibrate overnight prior to filtering onto a $25 \mathrm{~mm}$ diameter, $0.1 \mu \mathrm{m}$ pore size Anodisc filter. SERS spectra of these 
bacteria are shown in Figure 6. The number of cells present on the filters is indicated in the figure caption. For all spectra, the fluorescence background is not high. This indicates that the cell wall has not been degraded. As shown in the spectra, the different bacterial species and strains exhibit the same spectral peaks, however the intensities of these peaks vary.

The cell envelope of a bacterium is complex and provides protection for the bacterium while allowing selective passage of nutrients from the outside and waste products from the inside [30]. For Gram-negative bacteria, the cell envelope has three principal layers - the outer membrane (OM), the peptidoglycan cell wall, and the cytoplasmic or inner membrane (IM). The $\mathrm{OM}$ is a lipid bilayer that contains phospholipids that are confined to the inner leaflet of the membrane. The outer leaflet of the $\mathrm{OM}$ is composed of glycolipids. The OM contains lipoproteins; $\beta$-barrel proteins ( $\beta$ sheets wrapped into cylinders); and a few enzymes [30]. Directly attached to the outside of the OM is the S-layer which is comprised of a monomolecular array of proteins or glycoprotein subunits [31]. This S-layer stabilizes the membrane and has molecular sieve and barrier functions. The peptidoglycan cell wall is made up of repeating units of the disaccharide $\mathrm{N}$-acetyl glucosamine-N-acetyl muramic acid, which are cross-linked by pentapeptide side chains [30]. The IM is a phospholipid bilayer [30]. Consequently, there are amine, sulfhydryl, and carboxyl groups present on the surface of the bacteria available to bind to the Ag NPs. However, it has been shown that the SERS spectra of bacteria are dominated by peaks due to the adenine moieties of flavins [9, 11, 20]. In Figure 6a peaks at $\sim 730$ and $\sim 1330$ $\mathrm{cm}^{-1}$, indicated by $*$, are typical Raman signatures of adenine $[9,11]$. Recently Premasiri et al. [32] have shown that SERS spectra of bacterial species, obtained using Au NPs, contain spectral features due to hypoxanthine, xanthine, guanine, uric acid, adenosine monophosphate (AMP), and adenine. This suggests that the $\mathrm{Au}$ and Au NPs have a strong affinity for these purine compounds and preferentially interact with them. However flavins, which play an important role in many electron transfer reactions, are present on the interior of the cell wall $[9,20]$. In order to interact with the Ag NPs, these compounds need to be released from the cell. Premarsiri et al. [32] used SERS to show that flavin compounds were present in samples of the supernatant collected as a result of washing the bacteria. These samples were filtered through a $0.22 \mu \mathrm{m}$ filter to remove bacterial cells prior to obtaining the SERS spectra. From this they concluded that the flavins present in the supernatant had been secreted from the bacterial cells and had collected in 
their exogenous regions. Cyclic voltammetry [33] and HPLC [34], followed by UV-VIS spectroscopy and LC-MS, showed that Shewanella species secreted flavins. It was further shown that flavin adenine dinucleotide (FAD) was the predominant intracellular flavin but was not released by live cells [34]. HPLC also showed that wild strains of E. coli also secreted flavins [35]. The secreted flavins were shown to mediate extracellular electron transfer.

\section{CONCLUSIONS}

This communication describes a simple method of preparing SERS substrates to obtain SERS spectra of bacteria that eliminates citrate interference from the silver colloid preparation. In this method, citrate generated silver colloid and a bacterial suspension in borate buffer are mixed and allowed to incubate for at least an hour. This incubation time allows the Ag NPs to partition through the capsule to bind to the surface of the cell wall. After incubation, the bacteriaAg NP suspension is filtered onto a ceramic filter. Sharp, intense spectra were obtained by rastering the laser over the surface of the substrate. Rastering greatly increases both sensitivity and resolution. When non-overlapping areas on the SERS substrate were interrogated, the resultant spectra due to the bacteria were similar in both the intensity and position of the peaks. This indicated that the distribution of bacteria on the SERS substrate was homogeneous. It was found that the optimum ratio of bacterial suspension (containing $10^{7}-10^{8}$ cells $\mathrm{mL}^{-1}$ ) to silver colloid prepared using the Lee-Meisel process was 1:1. With respect to shelf life, samples, when stored in a refrigerator, remain SERS active for over several months. SERS samples made from different cultures of the same species of bacteria yielded similar spectra showing that this method of preparing samples is reproducible. SERS spectra of different species/strains of bacteria exhibited the same spectral peaks however their intensities varied. These spectra were dominated by the spectral signatures of flavins.

\section{ACKNOWLEDGMENTS}

This effort was funded by SPAWAR Systems Center Pacific's ILIR program. The authors would like to thank Orianna Bretschger (JCVI, San Diego, CA) and Olga Zaborina (University of Chicago, IL) for providing them with $S$. putrefaciens CN32 and P. aeruginosa P1, P2, and $\Delta \mathrm{mrtv}$, respectively. 


\section{REFERENCES}

[1] P.A. Mosier-Boss, K.C. Sorensen, R.D. George, A. Obraztsova, Spectrochim. Acta Part A. 153 (2016) 591-598.

[2] http://www.wysri.com/wp-content/uploads/2014/12/ORS-SERS-White-Paper.pdf

[3] Y. Zhang, F. Wang, H. Yin, M. Hong, Advances in Nanoparticles 13 (2013) 104-111.

[4] E. Vinogradova, A. Tlahuice-Flores, J.J. Velazquez-Salazar, E. Larios-Rodriguez, M. JoseYacaman, J. Raman Spectrosc. 45 (2014) 730-735.

[5] C.H. Munro, W.E. Smith, M. Garner, J. Clarkson, P.C. White, Langmuir 11 (1995) 37123720 .

[6] P. Pinkhasova, H. Chen, M.W.G.M. Verhoeven, S. Sukhishvili, H. Du, RSC Advances 3 (2013) 17954-17961.

[7] S. Efrima, B.V. Bronk, J. Phys. Chem. B 102 (1998) 5947-5950.

[8] L. Zeiri, B.V. Bronk, Y. Shabtai, J. Czégé, S. Efrima, Colloids and Surfaces A 208 (2002) 357-362.

[9] L. Zeiri, B.V. Bronk, Y. Shabtai, J. Eichler, S. Efrima, Appl. Spectrosc. 58 (2004) 33-40.

[10] M. Kahraman, M. Müge Yazici, F. Şahin, Ö.F. Bayrak, M. Çulha, Appl. Spectrosc. 61 (2007) 479-85.

[11] M. Kahraman, K. Keseroğlu, M. Çulha, Appl. Spectrosc. 65 (2011) 500-506.

[12] R.M. Jarvis, R. Goodacre, Anal. Chem. 76 (2004) 40-47.

[13] X. Yang, C. Gu, F. Qian, Y. Li, J.Z. Zhang, Anal. Chem. 83 (2011) 5888-5894.

[14] Y.R. Chen, Y. Liu, X. Nou, K. Chao, NSTI-Nanotech 20072 (2007) 549-552.

[15] C. Lee, D. Meisel, J. Phys. Chem. 86 (1982) 3391-3395.

[16] W. R. Premasiri, Y. Gebregziabher, L.D. Ziegler, Appl. Spectrosc. 65 (2011) 493-499.

[17] http://wysri.com/Sierra/

[18] D. McShan, P.C. Ray, H. Yu, J. Food and Drug Analysis, 22 (2014) 116-127.

[19] H. Zhou, D. Yang, N.P. Ivleva, N.E. Mircescu, R. Niessner, C. Haisch, Anal. Chem. 86 (2014) 1525-1533. 
[20] T. Smith-Palmer, C. Douglas, P. Fredericks, Vibra. Spectrosc. 53 (2010) 103-106.

[21] K.E. Stephen, D. Homrighausen, G. DePalma, C.H. Nakatsu, J. Irudayaraj. Analyst 137 (2012) 4280-4286.

[22] M.A. Ansari, H.M. Khan, A.A. Khan, M.K. Ahmad, A.A. Mahdi, R. Pai, S.S. Cameotra. J. Basic Microbiol. 53 (2013) 1-11.

[23] G. Nam, S. Rangasamy, B. Purushothaman, J.M. Song. Nanomater. Nanotechnol. 5 (2015) 23: $1-14$.

[24] S. Agnihotri, S. Mukherji, S. Mukherji. Nanoscale. 5 (2013) 7328-7340.

[25] P.R. Lambadi, T.K. Sharma, P. Kumar, P. Vasnani, S.M. Thalluri, N. Bisht, R. Pathania, N.K. Navani. Internat. J. Nanomed. 10 (2015) 2155-2171.

[26] J. Chen, S. Li, J. Luo, R. Wang, W. Ding. J. Nanomater. 2016 (2016) 7135852: 1-15.

[27] N. Durán, P.D. Marcato, R. De Conti, O.L. Alves, F.T.M. Costa, M. Brocchi. J. Braz. Chem. Soc. 21 (2010) 949-959.

[28] S. Sanyasi, R.K. Majhi, S. Kumar, M. Mishra, A. Ghosh, M. Suar, P.V. Satyam, H. Mohapatra, C. Goswami, L. Goswami, Scientific Reports 6 (2016) 24929: 1-16.

[29] K. Jann, B. Jann. Can. J. Microbiol. 38 (1992) 705-710.

[30] T.J. Silhavy, D. Kahne, S. Walker. Cold Spring Harb. Perspect. Biol. 2 (2010) a000414: 116.

[31] U.B. Sleytr, B. Schuster, E.-M. Egelseer, D. Pum. FEM Microbiol. Rev. 38 (2014) 823-864.

[32] W.R. Premasiri, J.C. Lee, A. Sauer-Budge, R. Théberge, C.E. Costello, L.D. Ziegler. Anal. Bioanal. Chem. 408 (2016) 4631-4647.

[33] E. Marsili, D.B. Baron, I.D. Shikhare, D. Coursolle, J.A. Gralnick, D.R. Bond. PNAS 105 (2008) 3968-3973.

[34] H. von Canstein, J. Ogawa, S. Shimizu, J.R. Lloyd. Appl. Environ. Microbiol. 74 (2008) 615-623.

[35] M.J. McAnulty, T.K. Wood. Bioengineered 5 (2014) 1-7. 
Table 1. Assignments of the peaks observed in the citrate SERS spectra shown in Figure 3a [3].

\begin{tabular}{|c|c|}
\hline Frequency $\left.\mathbf{( c m}^{-1}\right)$ & Assignment $^{\mathbf{a}, \mathbf{b}}$ \\
\hline 1386 & $v_{\mathrm{s}}(\mathrm{COO})$ \\
\hline 1292 & $\delta(\mathrm{COO})$ \\
\hline 1075 & $v(\mathrm{C}-\mathrm{O})$ \\
\hline 1020 & $v(\mathrm{C}-\mathrm{O})$ \\
\hline 944 & $v(\mathrm{C}-\mathrm{COO})$ \\
\hline 833 & $v(\mathrm{C}-\mathrm{COO})$ \\
\hline 795 & $v_{\mathrm{a}}(\mathrm{CCCC}-\mathrm{O})$ \\
\hline 741 & $v_{\mathrm{oop}}(\mathrm{COO})$ \\
\hline $570(\mathrm{broad})$ & $v_{\text {ip }}(\mathrm{COO})$ \\
\hline
\end{tabular}

a. $\quad v=$ stretch; $\delta=$ deformation

b. subscripts: $\mathrm{s}=$ symmetric, $\mathrm{a}=$ asymmetric, $\mathrm{oop}=$ out of plane, ip $=$ in plane 


\section{FIGURE CAPTIONS}

Figure 1. SERS spectra obtained by mixing E. coli with citrate generated Ag NPs prior to filtering onto a $25 \mathrm{~mm}$ diameter, $0.02 \mu \mathrm{m}$ pore size Anodisc filter. Spectra were obtained by rastering the laser over the sample and using a laser power of $30 \mathrm{~mW}$. (a) SERS spectrum of citrate that coats the citrate generated Ag NPs (average ten $2 \mathrm{~s}$ spectra ). (b) Samples were prepared by mixing $1.5 \mathrm{~mL}$ of citrate-generated Ag NPs with $1.5 \mathrm{~mL}$ of an E. coli suspension (total number of cells is $4.5 \times 10^{8}$ ) and allowing to equilibrate for $1 \mathrm{hr}$ (black, average ten $2 \mathrm{~s}$ spectra) and overnight (gray, average ten $3 \mathrm{~s}$ spectra) prior to filtering onto a $25 \mathrm{~mm}$ diameter, $0.02 \mu \mathrm{m}$ pore size Anodisc filters. (c) Sample was prepared by mixing $1 \mathrm{~mL}$ of citrate-generated Ag NPs with $1 \mathrm{~mL}$ of an E. coli suspension (total number of cells is $3.4 \times 10^{8}$ ) and allowing to equilibrate for $1 \mathrm{wk}$ prior to filtering onto a $0.02 \mu \mathrm{m}$ pore size Anodisc filter. Spectrum is the result of averaging ten $3 \mathrm{~s}$ spectra.

Figure 2. SERS spectra obtained by mixing $500 \mu \mathrm{L}$ E. coli (cell number is $9.5 \times 10^{7}$ ) with different volumes of citrate generated Ag NPs. Volumes of Ag NPs are indicated. The samples were allowed to equilibrate overnight prior to filtering onto a $13 \mathrm{~mm}$ diameter, $0.1 \mu \mathrm{m}$ pore size Anodisc filter. Spectra were obtained by rastering the laser over the sample and using a laser power of $30 \mathrm{~mW}$. The $250 \mu \mathrm{L}$ spectrum was obtained by averaging ten $5 \mathrm{~s}$ spectra, the $500 \mu \mathrm{L}$ spectrum by averaging ten $3 \mathrm{~s}$ spectra, and the 1000 and 1500 spectra by averaging ten $4 \mathrm{~s}$ spectra.

Figure 3. SERS spectra obtained for E.coli. The sample was prepared by mixing $1.5 \mathrm{~mL}$ of citrate-generated Ag NPs with $1.5 \mathrm{~mL}$ of an E. coli suspension (total number of cells is $4.5 \times 10^{8}$ ) and allowing to equilibrate for $1 \mathrm{hr}$ prior to filtering onto a $25 \mathrm{~mm}$ diameter, $0.02 \mu \mathrm{m}$ pore size Anodisc filter. (a) Spectra obtained using the single point mode (gray) and with rastering of the laser (black). Spectra were obtained using a laser power of $30 \mathrm{~mW}$, and averaging ten $3 \mathrm{~s}$ spectra.

(b) Spectra obtained for five non-overlapping regions on the substrate. Spectra were obtained by rastering the laser over the sample, using a laser power of $30 \mathrm{~mW}$, and averaging ten $2 \mathrm{~s}$ spectra. 
Figure 4. SERS spectra obtained for $E$. coli over a five month period. The sample was prepared by mixing $1.5 \mathrm{~mL}$ of citrate-generated Ag NPs with $1.5 \mathrm{~mL}$ of an E. coli suspension (total number of cells is $4.5 \times 10^{8}$ ) and allowing to equilibrate for overnight prior to filtering onto a 25 $\mathrm{mm}$ diameter, $0.02 \mu \mathrm{m}$ pore size Anodisc filters. Spectra were obtained by rastering the laser, using a laser power of $30 \mathrm{~mW}$, and averaging ten $1 \mathrm{~s}$ spectra.

Figure 5. SERS spectra obtained for three different cultures of E. coli, designated (a), (b), and (c), as a function of cell number. For culture (a) $4 \mathrm{~mL}$ of $E$. coli suspension and $1.5 \mathrm{~mL}$ of citrate-generated $\mathrm{Ag}$ NPs were mixed. For cultures (b) and (c), equal volumes of bacterial suspension and citrate-generated Ag NPs were mixed. Samples of all three cultures were allowed to equilibrate overnight and were filtered onto $0.1 \mu \mathrm{m}$ pore size Anodisc filters. Spectra were obtained by rastering the laser and using a laser power of $30 \mathrm{~mW}$. Filter diameter, number of cells, number of spectra averaged, and acquisition times are indicated.

Figure 6. SERS spectra of (a) E. coli ATCC $\left(4.5 \times 10^{8}\right.$ cells, average ten $2 \mathrm{~s}$ spectra), (b) Shewanella putrefaciens CN32 $\left(3.12 \times 10^{8}\right.$ cells, average $105 \mathrm{~s}$ spectra), (c) Pseudomonas aeruginosa $P 1\left(3.08 \times 10^{8}\right.$ cells, average ten $5 \mathrm{~s}$ spectra), (d) Pseudomonas aeruginosa P2 $\left(3.69 \times 10^{8}\right.$ cells, average ten $5 \mathrm{~s}$ spectra), and (e) Pseudomonas aeruginosa $\Delta m v t r\left(2.13 \times 10^{8}\right.$ cells, average ten $4 \mathrm{~s}$ spectra). Spectra were obtained by rastering the laser over the substrates and using a laser power of $30 \mathrm{~mW}$. Peaks due to adenine moieties are indicated by *. 


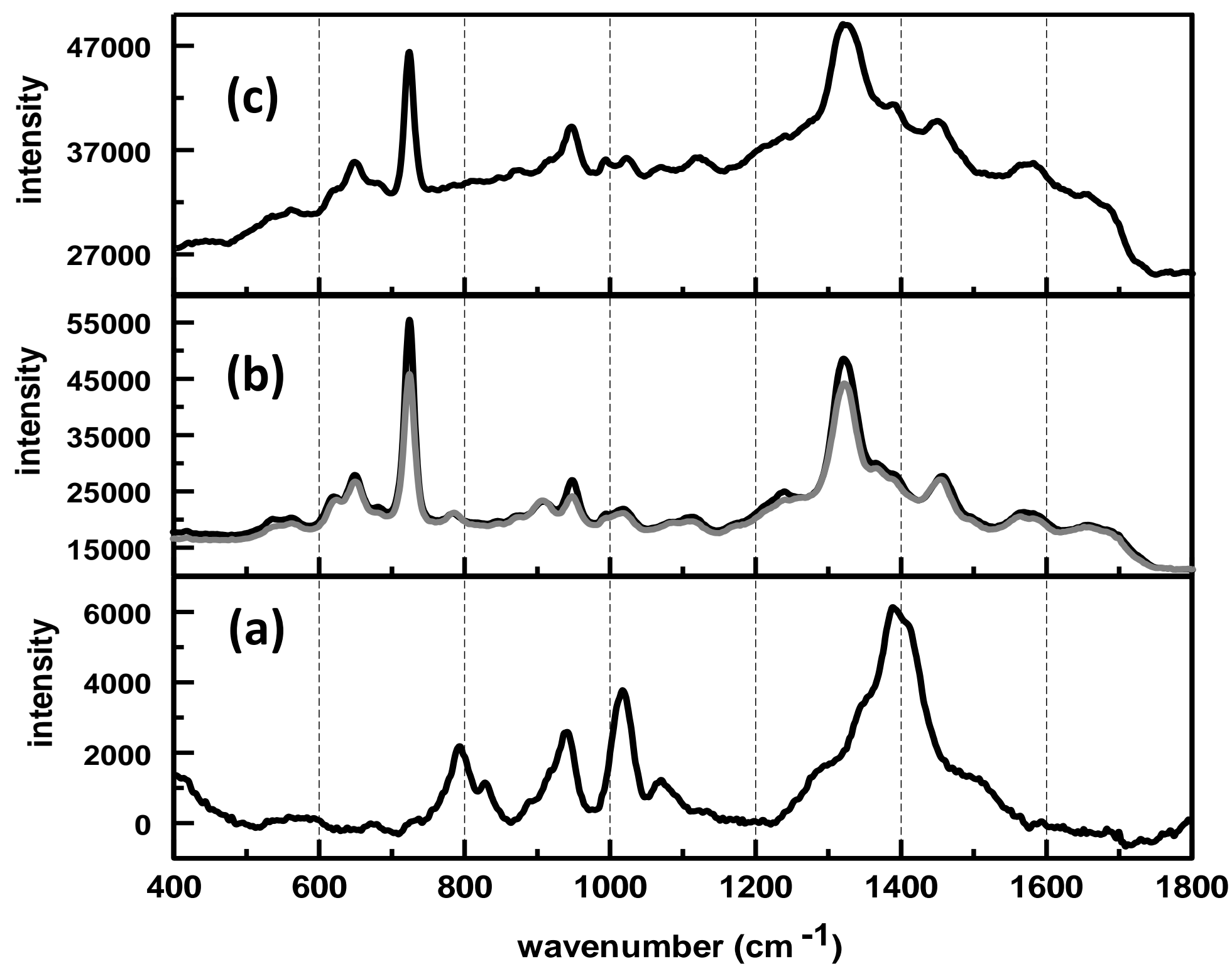




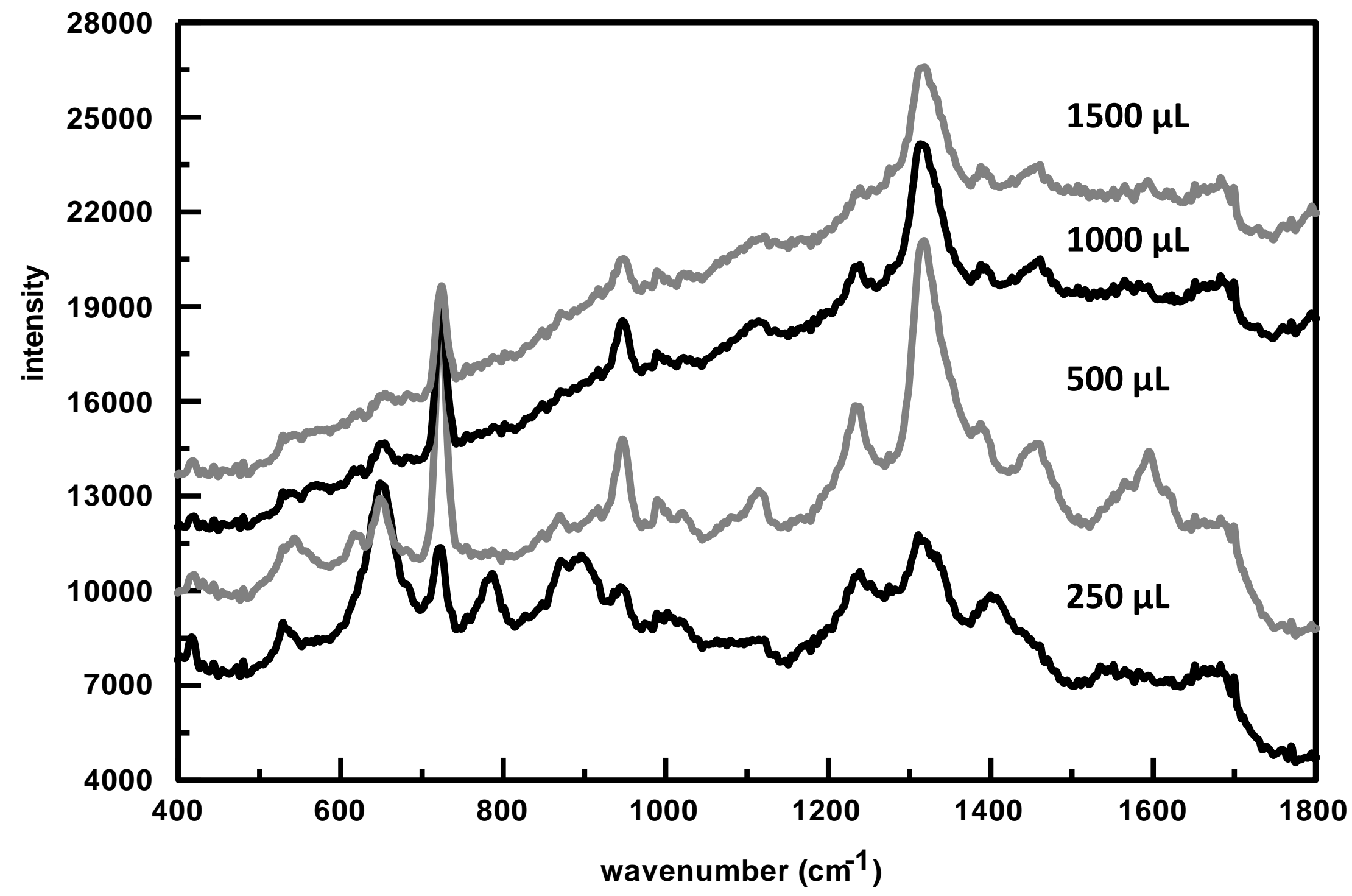


(a)

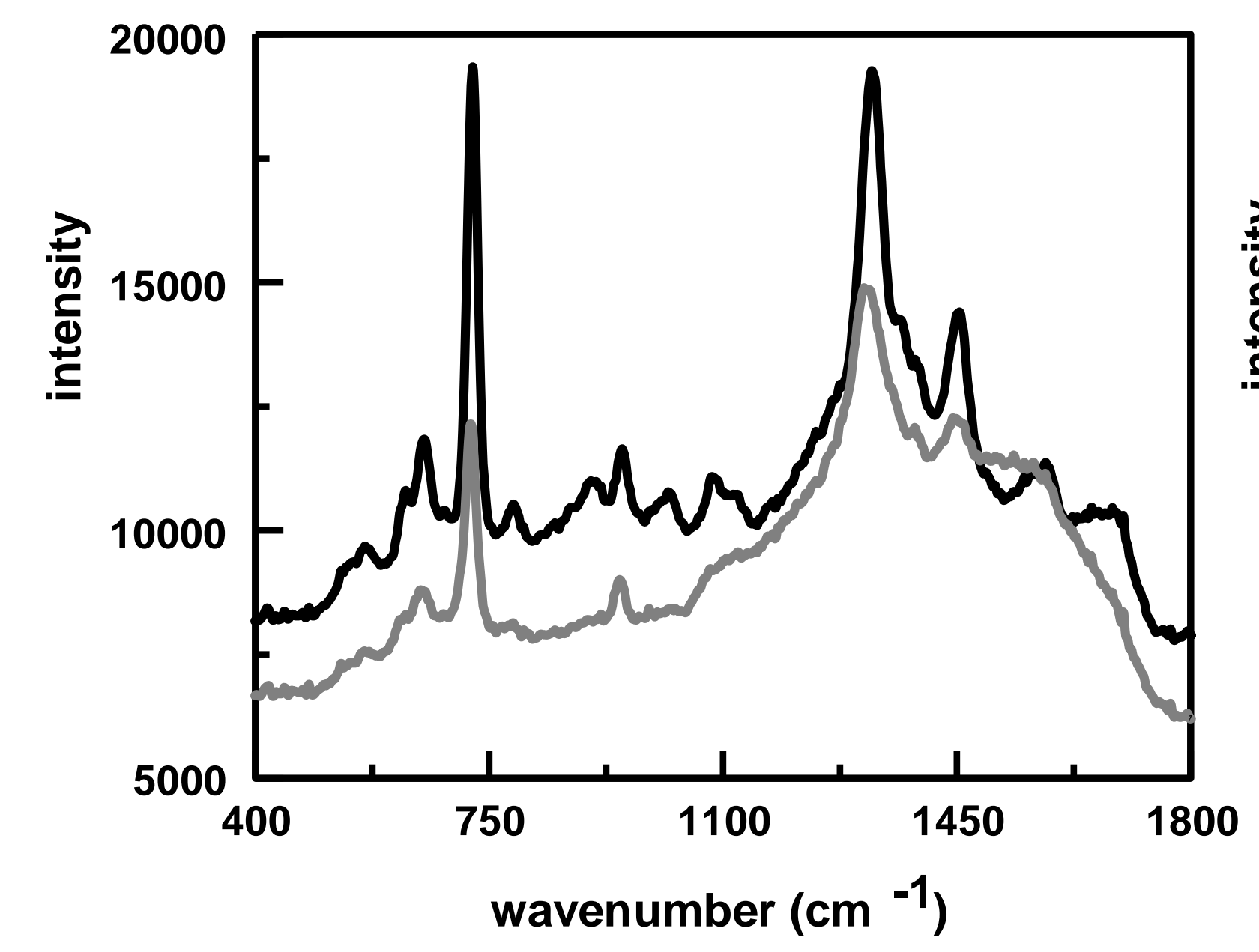

(b)

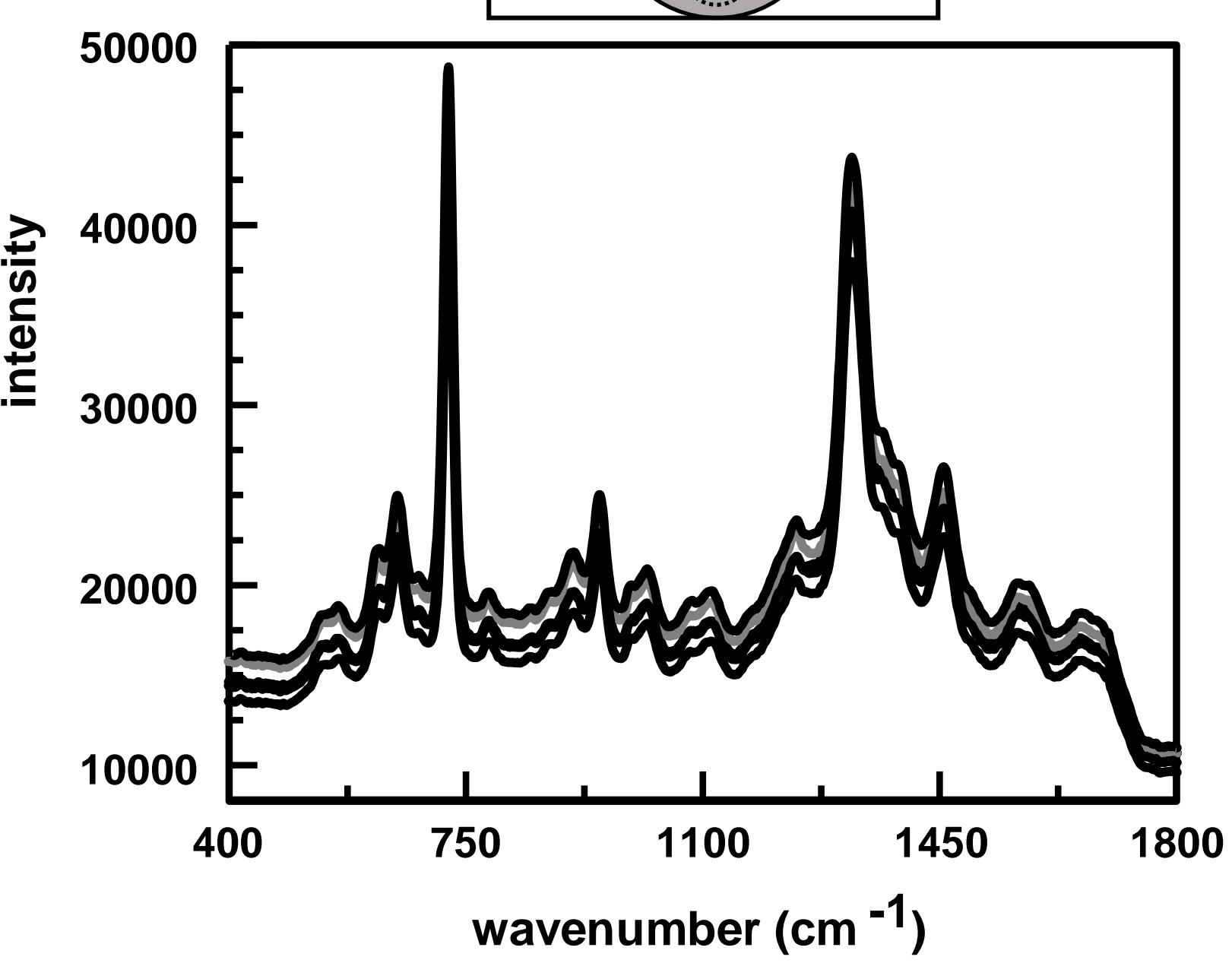




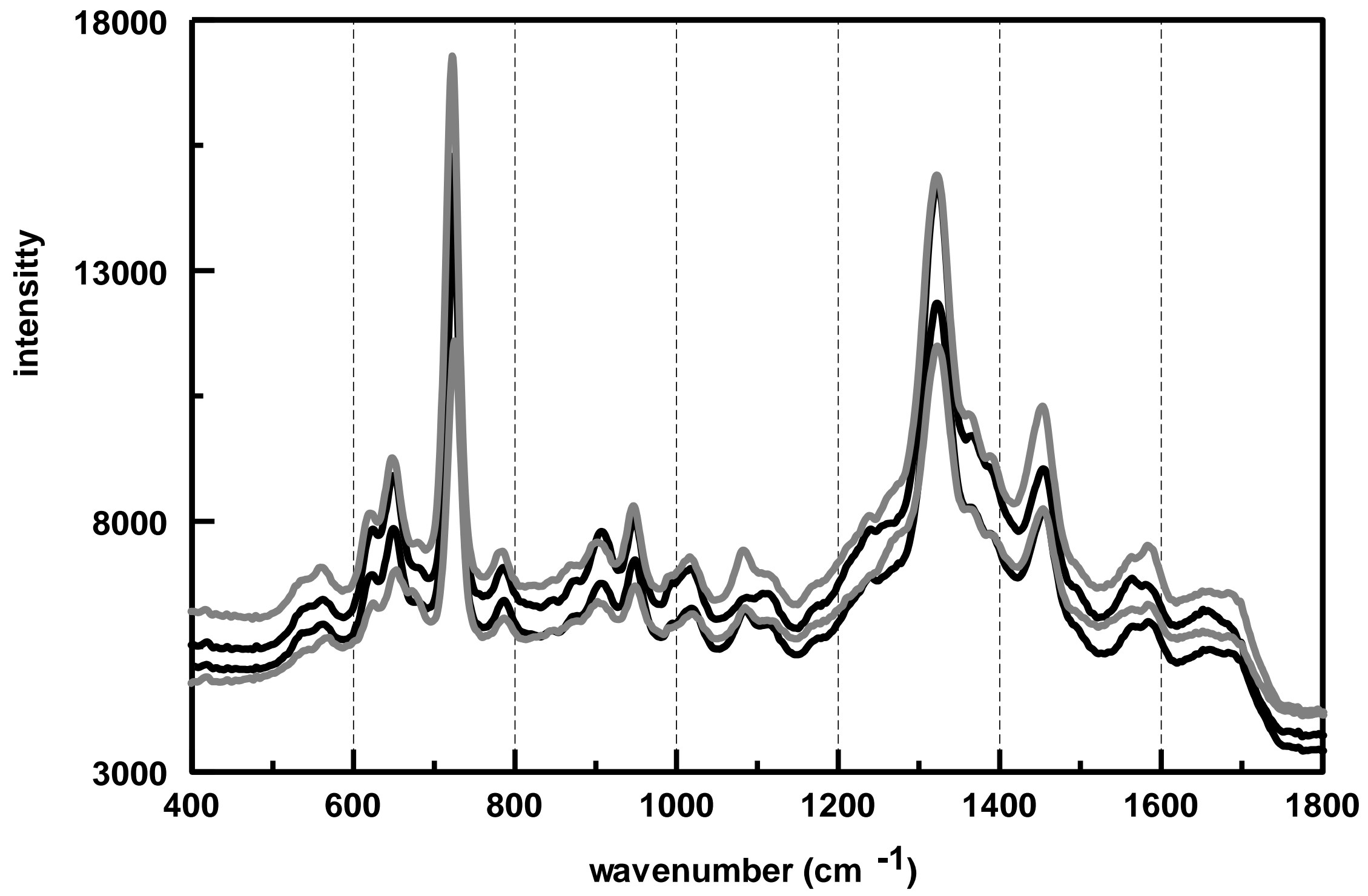


(b)

(a)

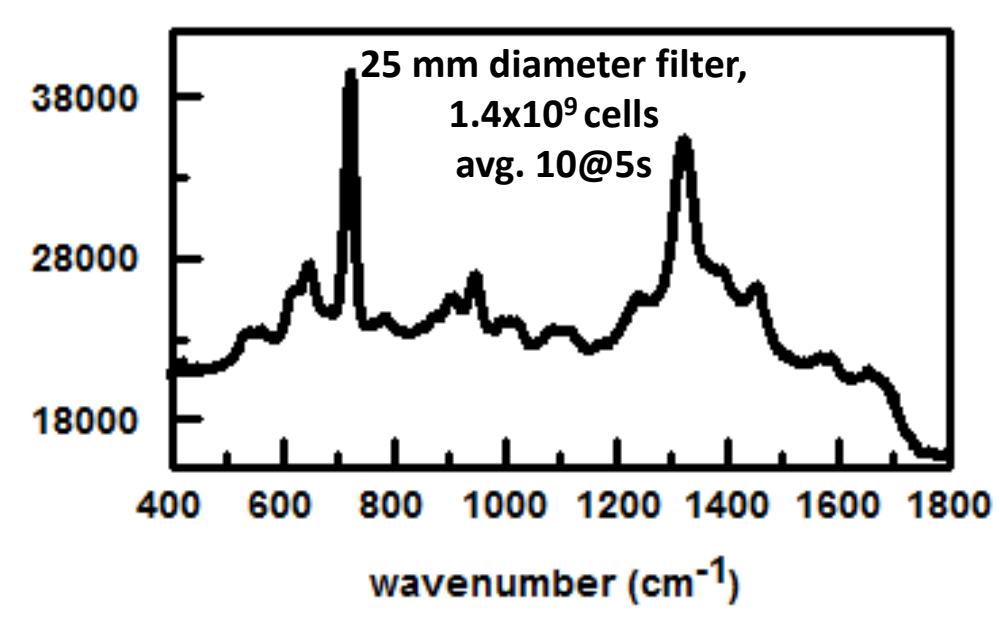

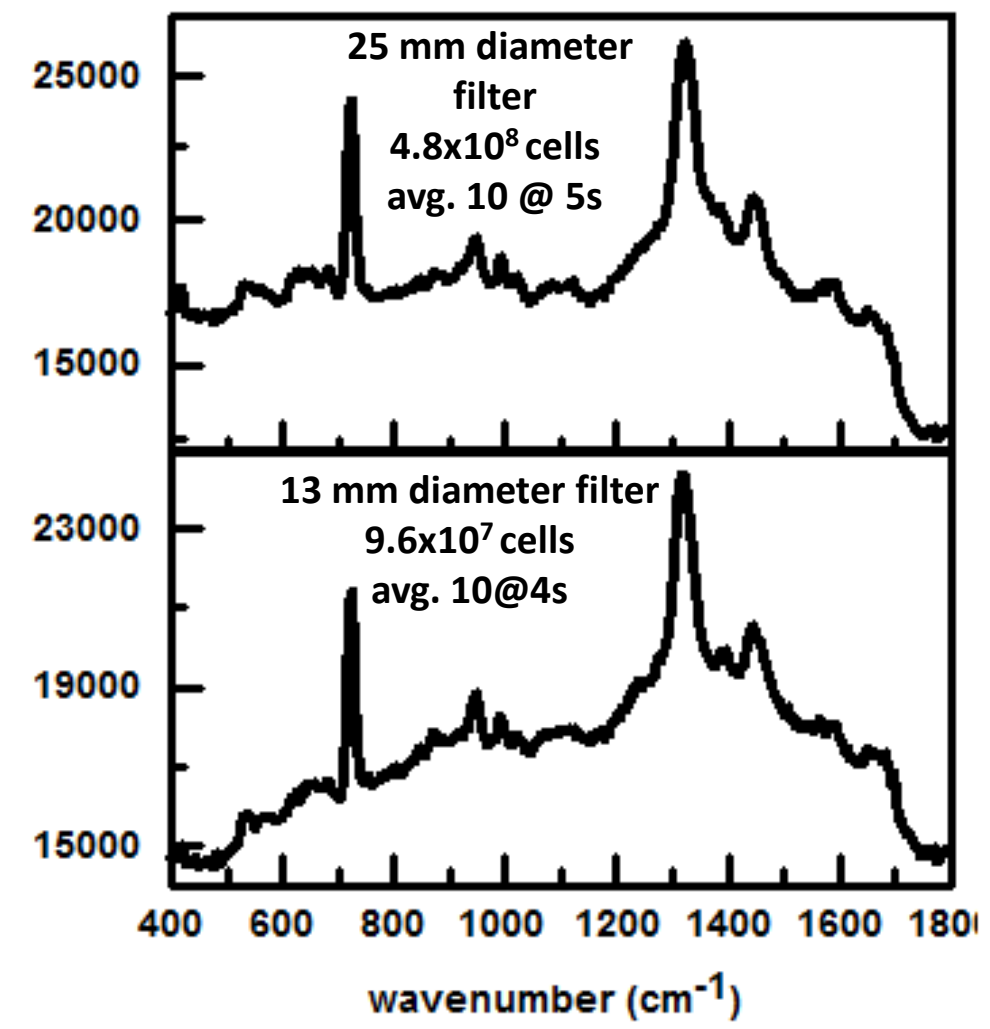

(c)

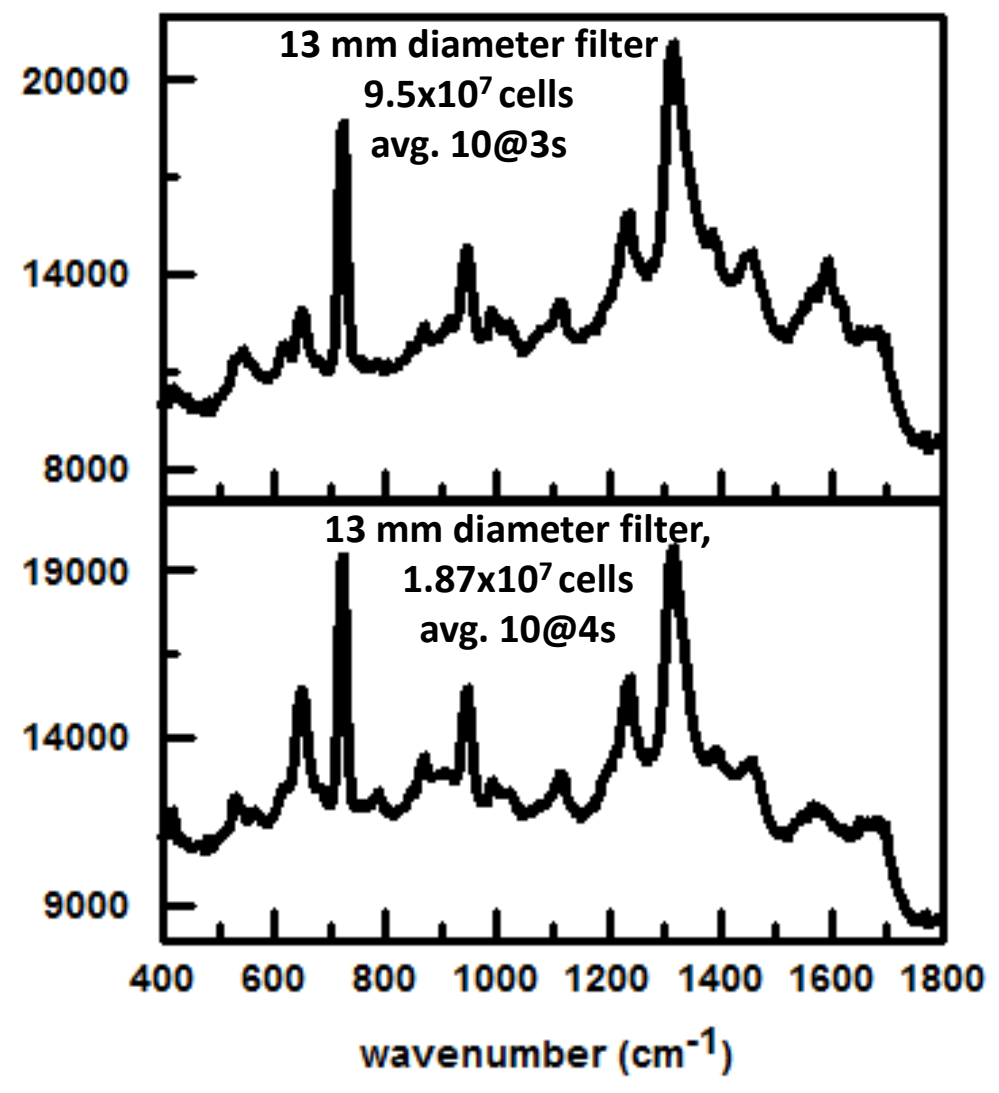



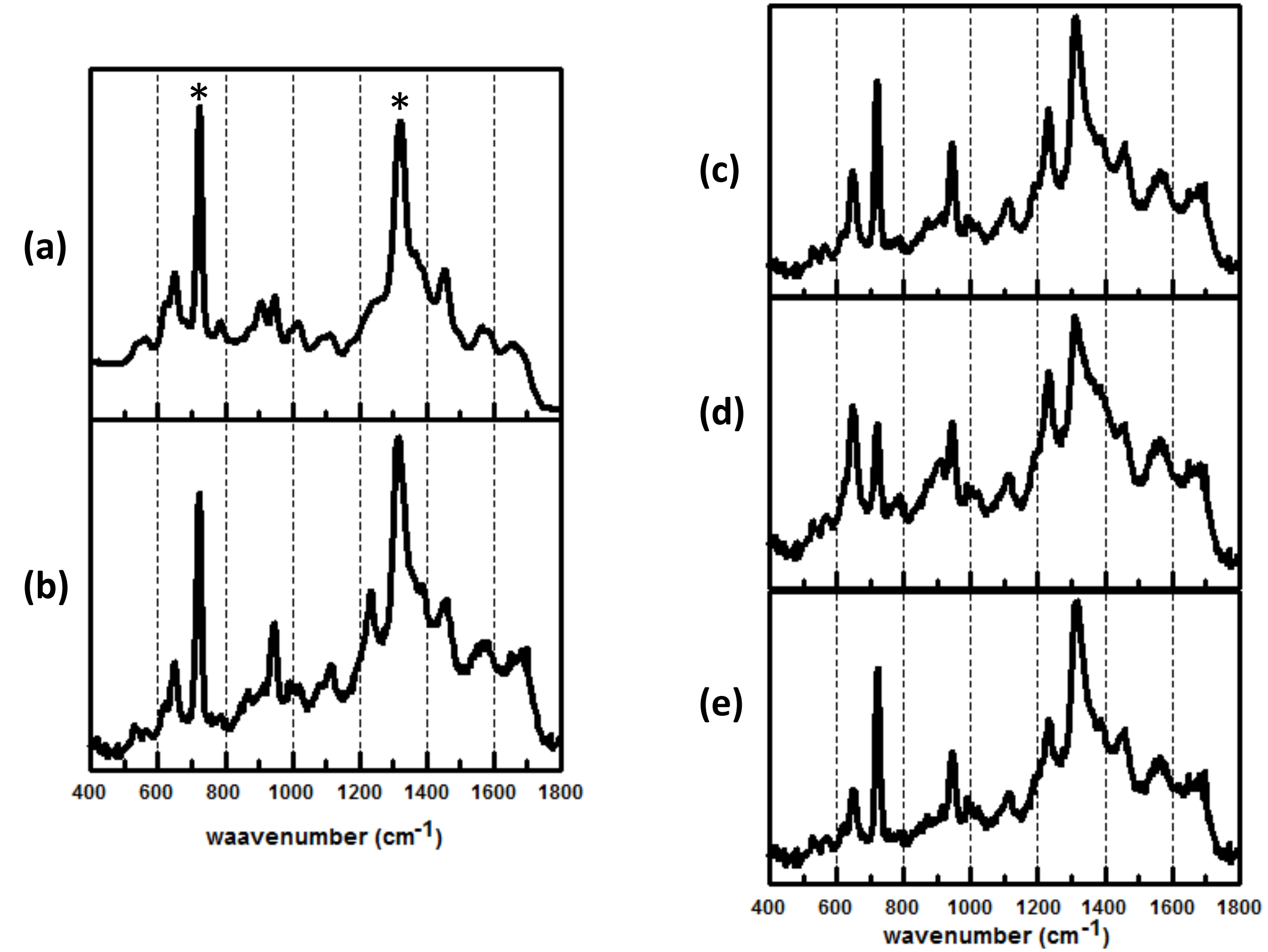